\title{
Employment Psychological Analysis of College Students
}

\author{
Aiqing Meng \\ Dezhou University \\ 566 University West Road, Dezhou 253023, Shandong, China \\ Tel: 86-534-8985-031Ｅ-mail: mengaq1198@163.com
}

\begin{abstract}
Employment crisis of college students has brought a certain psychological barrier. They can neither avoid nor underestimate such issues, but they should adjust their mentality by themselves, and go away from the employment mental mistakes in order to actively respond to the current employment situation.
\end{abstract}

Keywords: College students, Employment, Psychological adjustment

Since the college graduates employment system has been changed from the model of "uniform contract and distribution" to "supply and demand meet, two-way choice, and independent career choice", their career and employment has become an unavoidable practical problem. A series of issues imposed by the contradictions between opportunities and challenges, personal expertise and social needs is a psychological test for college students, and how are their psychological qualities? Those qualities have a great impact on the determination and accomplishment of the employment goals. For college graduates, the job market is a new and exotic space. When in face of tough competition in the employment for the first time, there tend to be some blind spots and errors in their mentality.

\section{Common employment psychological problems of college students}

\subsection{Extortionate high career expectations}

In recent years, due to the affection and interference by many factors, extortionate high career expectations among college students are universal mind. More than $90 \%$ of the students wish to opt for units with good benefits, and high wage level; more graduates required to work in the big developed cities. Those indicated that the students failed to have a correct understanding and analysis of their own position in society. Conducting personal social positioning, they should carefully consider various integrated factors such as their own knowledge and ability levels, professional social adaptability, and their own personality traits and so on.

\subsection{Employment anxiety and fear}

They were mainly presented as follows: on one hand they were eager to embark on the community as soon as possible, and seek ideal career to fit themselves; on the other hand, they were swayed by considerations of gain and loss, reluctant to leave school, and felt uncertainty to embark on the community. Their anxiety and fear were mental experiences due to their conscious of the contradictions between employment objective situation and subjective self-recommendation.

\subsection{Negative self-esteem}

Due to the competitions with a large number of doctoral students in society, resultant self-esteem was particularly prominent. Students with passivity should undertake active self-implications before employment and strive to overcome the kind of inferiority complex.

\subsection{Employment blind obedience and impulse}

Some students can not objectively analyze the needs of society, and lacked of confidence on their own competitiveness. Consequently, a drift of blind obedience psychology occurred in their employment. When seeking jobs, they lacked of confidence and courage, tended to be circumspect and parrots, and go along with others without their own views. Some students even showed an extreme emotion. They were disturbed by multiple career factors, and lacked of a due calmness and self-control. They tended to be of emotional impatience, blind comparisons, and full resentment, lacked of job planning, and often made unthinking responses to a variety of information.

\subsection{Thinking set and perfection}

Most students wished to get jobs in one step in employment, but they could only find the positions which they played at their best in the course of their work. Therefore, "First employment, then the career" could allowed 
graduates to gradually find their own career development in the course of their work. It is not necessary for students to care about how high the first step is when they steps out of schools. Many graduates haven't social experiences and they are not sure of their favorite kind of work environment and positions, accordingly, it is of certain difficulty for them to find an ideal job. The thinking of "professional counterparts" and the "iron rice bowl" have constrained the career scopes of graduates. They worried about career choices, considered too much carefully, and tended to be afraid of taking risks and lack of risk awareness and tolerance, and thus hampered the effective self-promotion.

\subsection{Being afraid of hard-work, and blind pursuit of the enjoyment}

Many college students had the psychology of being afraid of hardship, and blind pursuit of the enjoyment. They even paid more attention to the fame and fortune in employment affected by the impact of social utilitarianism, had some deviations on the views of money and fame and fortune, lacked of objective self-evaluation, failed to consider the employing unit's requirements of specialty, capacity, level, and so on in the new situation, and blindly pursued high-treatment.

\subsection{Paying no attention to improving their own quality, and being wild about propping up the relationship}

Many students had a very strong psychological dependence, failed to be based on their own efforts, ignored the cultivation and improvement of their own quality, but rather keened on the relationship and relied on families and friends to find ways for them.

\subsection{Overvaluation of themselves, and being pretentious}

Some college students counted on having strong points, said that "moon to be useful", valuated them to an excessively high level, and often measured the career needs of the community according to their personal subjective criteria in employment. Therefore, the consequences were usually underachievement.

\subsection{Over-dependent}

Some students lacked of independence, and had over-reliance psychology in employment. One is to over-depend on the school, and their ideas still remain in the original model of "uniform contract and distribution", and until now there are still ideas such as job assignment after graduation. They didn't seek work units actively, and waited for the school to introduce. The other is to over-depend on family and friends, we always could find students accompanied by their parents wandering in front of the booth of employing units in various talent exchange meetings.

\subsection{Weak legal consciousness}

During the process of selecting employing units, some students came with the attempts of "riding the donkey and looking for horse", namely regardless of whether good or bad the employing unit is, signed with them first, and then continued to accept the selection of other units. Once a slightly good unit appeared, they would take the long road of breaking contract. Some graduates were sincere when singing the agreements. Once finding a better unit, they would want to ruin the agreement they have been singed previously. Once graduates signed an employment agreement with employing units, the agreement would have the force of law. If graduates failed to get consent of the origin unit or school employment department, they were not allowed to cancel the agreement unilaterally to replace the unit without permission. During the employing process, they should learn to use legal means to protect their legitimate rights and interests, and guarantee they would not be violated.

\section{Self-adjustment of college students' psychology}

Students had the psychology such as "being swayed by considerations of gain and loss", confusion and perplexity, and other employment psychological conditions. Once the employment was rebuffed, they would be immediately frustrated, and complained, which thus affected their normal life and learning.

Students should recognize that life is not only a continuous evolving process, but also the course of adapting to the environment. During certain stages in life, due to the changes of environmental conditions, society would propose newer and higher requirements for individuals, which would make they feel tough to adapt. At this moment, if the individuals were able to change their own or the environment actively and consciously and maintain coordination with the environment, they could get through the difficulties and go into the next phase of a new life smoothly. On the contrary, if they failed to adjust themselves to meet the environmental requirements, they would not overcome certain limitations of the environment and get through the difficulties. Consequently, trapping phenomena would appear on the road of the development. The longer the delaying is, the greater the difficulties of adaptation are. This would affect not only their own current situation, but also their lives; this would not only affect the career effects, but also endanger the physical and mental health. Therefore, to maintain 
a good career mentality is very crucial. Thus, students should learn to use psychological adjustment to undertake self-adaptation. The following three methods are worth advocating:

\subsection{Self-retreat method}

Calmness and rationality is an important indicator of whether people are mature or not. When encountering difficulties and setbacks, they should be calm, control their mood and refrain from impulse and impatient. They should carefully analyze whether it is the reasons of itself, or the employing units' requirements were too harsh. Calmly thinking is helpful to stabilize emotions; finding out the causes is in favor of solving the problem targeted.

\subsection{Appropriate method of self-vent}

For being anxious and nervous due to frustration, the simplest way is to "vent" and avoid the bad feelings buried in heart. The longer your worry was hidden, the greater your harm would be. A better approach is to talk with your friends or teachers, feel pleasant after unbosoming, and even weep before relatives and friends in order to obtain comfort and ease. Although there is the old saying that "The ball do not cry easily," but if necessary, weeping is also nothing wrong with man, and don't bury extreme pressure in heart. They could also go to play balls, climb mountains, and participate in the activities with a large amount of exercise. However, attention should be paid to moderation.

\subsection{Self-consolation method}

Self-consolation method is self-comforting, and in effect self-tolerance. When encountering difficulties and setbacks during the process of employment, they have done their best and still made no difference, they could persuade themselves to make certain concessions, not demand, and recognize and accept the reality in order to get relief.

\section{Set a good state of mind, and protect the successful placement}

In face of the employment and career, college students should consider what kind of professional position the community provided for their own, and how much chance and possibility they would have; meanwhile, they should consider how to understand themselves correctly, set a good state of employment mind, and adjust their employment psychology in order to make the best choice.

\subsection{Establish employment goals}

To establish the employment goal is the first step to maintain a good employment psychology, but also a key step. To establish employment goals should pay attention to two aspects: First, a correct understanding of themselves, namely objective analysis of their own interests and features, personality and temperament, ability levels, and awareness of what they want to do, what they can do and how is their competitive strength; Second, a correct understanding of the employment situation, namely consideration of how is the demand for their own major and the ideal profession in the community and how the competition intensity is; whether their ideal job are consistent with his own major or not, and if not, how to make up; what are the specific job requirements for employees imposed by the units, etc.

\subsection{Overcome inferiority and timidity, to establish self-confidence}

Self-confidence is a positive evaluation of oneself. They should believe that they possess the conditions required by certain professions, and participate in competition with enough courage.

\subsection{Be not afraid of setbacks, don't passively withdraw, and had a strong mental endurance}

Strong psychological endurance is indispensable in a competitive society, and it enables people to withstand setbacks, and keep an active and enterprising courage. College students will certainly be subjected to failures in the course of employment. In face of failure, some people felt uneasy, and lacked of energy, or even became inferior, which were all obvious performance of no strong psychological endurance. The real strong would reflect on lessons learned seriously and make efforts to seek for new opportunities in face of job failure.

\subsection{Increase their own contingency}

Contingency refers to that students adjust their employment expectations and knowledge and ability structure timely according to the actual situation in order to make the maximum flexibility with the demand of the employment market. With the rapid development of society, occupational categories and requirements will change faster and faster. The major some people learned was in short supply when they first entered the university, but was saturated when graduated, and even was hard to get employment. Consequently, one of the good approaches to reduce the employment troubles of college students is to enhance their contingency greatly. 
For example, to minor a second major or to learn the knowledge and skills required by the ideal occupation as much as possible.

\section{5 know yourselves and others in order to always win in employment}

Knowing yourself is a realistic evaluation of yourself, and to have a proper understanding of your own. One should objectively and correctly see their own advantages and disadvantages, strengths and weakness, and define their personality, interests and strengths. Knowing others is to understand the social environment and work units in employment, and to have a correct understanding of the employment situation faced and understand what kinds of university graduates the community requires. Make it clear what you want to do and what you can do.

3.6 Improve the psychological quality, and enhance the employment competitiveness

College students should train several psychological qualities as follows.

3.6.1 Professionalism. To have a strong dedication has become an important criterion for a modern enterprise to get employees, and professionalism is topped the list of examining candidates by recruitment units, followed by the manipulative abilities.

3.6.2 Have a sense of responsibility and a strong adaptability, and be determined and good at communication. Adaptability implied that the knowledge learned from the books not only adapts to the initiative of practical work, but also coordinates with the interpersonal relationships and living environment in harmony.

3.6.3 Team cooperation spirit. In this highly competitive society, a cardinal role played in doing a job well is not dominated by one's ability but the unity and assistance among group members.

3.6.4 Have a strong capacity of practical applied knowledge, and be well versed in law. Excluding the overall quality, the employers pay more attention to the capacity of practical applied knowledge and development potential in profession of the candidates. Graduates with a strong awareness of law are also more favored by the enterprises.

Taken together, with the rapid development of Chinese economy, the requirements of high-quality human resources by the society is bound to show a progressive trend, and then the employment situation of college students will gradually be ameliorated. The employment psychology and psychological perplexity will have been fundamentally changed along with the transformation of the increasing market-oriented employment ways and concepts. Consequently, college students have the correct employment psychology and concept, possess the employment skills to meet the needs of the society, and then have no difficulties in employment.

\section{References}

Zhang, D.J. (2004). Introduction of school mental quality education. Southwest China Normal University Press, 12.

Zhou, G.F. (2009). Methodology of students' career guidance. Economic Management Press, 3. 